\title{
Relações sociopolíticas brasileiras: análise gramsciana de elementos contextuais nacionais
}

\author{
Emilie Faedo Della Giustina \\ Universidade Estadual de Ponta Grossa (UEPG)
}

\author{
Danuta Estrufika Cantóia Luiz \\ Universidade Estadual de Ponta Grossa (UEPG)
}

Relações sociopolíticas brasileiras: análise gramsciana de elementos contextuais nacionais

Resumo: O presente artigo tem por objetivo compor um quadro contextual nacional, por meio da utilização do referencial teórico gramsciano, para interpretação do contexto sociopolítico brasileiro no que tange às relações democráticas. O recorte temporal é delimitado a partir do segundo quartel do século 20, marcado pelo período de redemocratização do país, até 2013, marcado pelas mobilizações em massa/protestos de rua. Trata-se de uma pesquisa bibliográfica sobre elementos contextuais das relações sociopolíticas brasileiras.

Palavras-chave: Estado. Sociedade Civil. Democracia no Brasil.

\section{Brazilian Socio-political relations: Gramscian analysis of National Contextual Elements}

Abstract: The purpose of this article is to compose a national contextual framework, by using Gramscian theoretical references to interpret the Brazilian socio-political context in terms of democratic relations. The timeframe is limited to the second portion of the twentieth century, marked by the period of redemocratization in Brazil, until 2013 and the mass street demonstrations. It is a bibliographic study about contextual elements of Brazilian socio-political relations.

Keywords: State. Civil society. Democracy in Brazil. 


\section{Introdução}

A temática do presente estudo se situa na compreensão sobre o modo como se organiza a sociedade civil brasileira na contemporaneidade, tempo histórico marcado por três décadas incompletas de redemocratização do país, e os efeitos sociopolíticos desta configuração. A configuração da sociedade civil brasileira apresenta uma diversidade de possibilidades de arranjos participativos, institucionalizados junto à esfera estatal ou não. Essa diversidade traz consigo variadas expressões de projetos ideo-sócio-políticos manifestos na configuração e atuação de organizações da sociedade civil.

A perspectiva teórica gramsciana de Estado e sociedade civil possibilita desenvolver análises que diferem de interpretações fragmentadoras da totalidade social, que os separam a fim de atender a uma intencionalidade ideológica própria do neoliberalismo. Gramsci elabora uma noção geral de Estado que assimila também elementos comuns à noção de sociedade civil, constituída pelo que denomina de aparelhos privados de hegemonia, os quais exercem função fundamental de elaboração de consensos necessários à dominação, e, movendo-se dialeticamente, também correspondem ao local de disputa pela hegemonia.

O presente artigo tem por objetivo compor um quadro contextual nacional, por meio da utilização de conceitos gramscianos, para interpretação do contexto sociopolítico brasileiro no que tange às relações democráticas. O recorte temporal estabelecido é delimitado a partir do segundo quartel do século 20, marcado pelo período de redemocratização do país, até 2013 quando as mobilizações em massa/protesto de rua somam-se de forma mais recorrente ao repertório de atuação da sociedade civil. Fundamentado na perspectiva teórica gramsciana é que se propõe refletir sobre o contexto sociopolítico nacional. Tarefa que demanda por um olhar histórico e estrutural da formação da realidade social brasileira, num entendimento de que o modo como a sociedade civil se expressa e se organiza na contemporaneidade é fruto da dinâmica estabelecida no processo histórico, do qual também é possível visualizar possibilidades e alternativas contra hegemônicas à mesma.

\section{Relações sociopolíticas brasileiras: análise gramsciana de elementos contextuais nacionais}

Gramsci (2006, p. 293), ao tratar acerca do processo de revolução passiva, ou revolução-restauração, o define como um "conservadorismo reformista temperado", como uma forma de moderantismo político que acomoda conservação e inovação por meio da redução da dialética a um processo de evolução reformista. Para Aggio (1998, p. 166), a revolução passiva é uma construção linguística propositalmente paradoxal que "expressa essencialmente uma combinação de continuidade e mudança ou uma dialética entre conservação e renovação". Trata-se de um processo de modernização que afeta o conjunto da sociedade, sem que haja uma transformação político social de caráter radical. Conceito propício para analisar a realidade brasileira a qual, no movimento histórico apresenta nuances de renovação, mas que quando analisadas criticamente demonstram forte caráter de conservação. Revolução passiva sublinha fortemente o momento superestrutural, em particular o momento político, para explicar transformações societárias e contribui para análise específica do processo de modernização capitalista no Brasil, em suas características elitista e antipopular, com exclusão das massas e forte protagonismo do Estado. Nas revoluções passivas, o Estado substitui os grupos sociais locais na função de dirigir uma luta de renovação.

Gramsci (2006, p. 393) define como um processo de reação das classes dominantes aos movimentos contra hegemônicos engendrados na sociedade civil, em períodos de crise de hegemonia. Esta reação dá-se através de "'restaurações' que acolheram uma certa parte das exigências que vinham de baixo; trata-se, portanto, de 'revoluções-restaurações', ou, ainda, 'revoluções passivas'”. Coutinho (1998) explica que o instrumento de transição pelo alto é o Estado, o que significa, em termos gramscianos, um fortalecimento da sociedade política (aparelhos militares e burocráticos de dominação e de coerção) enquanto permanece subalterna a sociedade civil (aparelhos privados de luta pela hegemonia). Em Gramsci (2006, p. 426), um processo de revolução passiva implica sempre o momento da restauração (que significaria uma reação à possibilidade de uma transformação radical) e da renovação (estratégia de assimilação de demandas populares pelas camadas dominantes): "A restauração torna-se a forma política na qual as lutas sociais encontram quadros suficientemente elásticos para permitir à burguesia chegar ao poder sem rupturas clamorosas".

O processo de modernização capitalista no Brasil acontece sem que hajam, necessariamente, rupturas revolucionárias de uma classe burguesa nacional, resultado de movimentos populares. A particularidade do contexto brasileiro é caracterizada por uma transformação capitalista fruto do acordo entre as classes economicamente dominantes, excluídas as forças populares e com recorrente utilização dos aparelhos repressivos e de intervenção econômica do Estado. Alinhando-se a uma das causas-efeitos da revolução passiva em que o Estado "substitui os grupos sociais locais, ao dirigir uma luta de renovação. É um dos casos em que esses 
grupos têm a função de 'domínio', e não de 'direção': ditadura sem hegemonia”' (GRAMSCI, 2002, p. 330). Ou seja, no Brasil há um fortalecimento do Estado em detrimento da sociedade civil, com ausência de uma iniciativa popular unitária no desenvolvimento da história.

A noção de revolução pelo alto coloca-se como marca de um processo que caracterizou diferentes momentos da história brasileira, desde a República Velha, passando pela revolução de 1930, até o golpe militar de 1964. Contextos nos quais as decisões foram tomadas de forma elitista e com exclusão das massas populares, prevalecendo os métodos de supremacia em detrimento das formas de hegemonia (SIMIONATTO, 2008). Momentos que evidenciam processos de modernização conservadora, característicos da particularidade da formação capitalista brasileira. Desenvolve-se no Brasil a capacidade de modernizar-se sem que ocorram rupturas de caráter transformador. O que se observa são mudanças que se amoldam, flexibilizam-se, num processo que Fernandes (1987) chama de revolução conservadora em que, a transição para a fase capitalista no Brasil sequer pode ser chamada de revolução burguesa, pois se trata de uma longa fase de transição, sem rupturas significativas dos estamentos que ocupam o poder. Há a incorporação do capitalismo moderno sem mudanças estruturais, movimento que Faoro (2000) ilustra como circular, que gira e volta para o mesmo lugar: uma viagem redonda. Conforme pontua Fernandes (1987, p. 80), "estamos diante de uma evolução histórica em que o 'setor velho' da economia não se transformou nem se destruiu para gerar o 'setor novo".

Traços da modernização conservadora que ocorre no país são expressos no plano imediatamente político, por meio da recorrente exclusão da participação popular nos processos de decisão política. Ou seja, a formação da cultura política das relações estabelecidas entre Estado e sociedade civil no país são determinadas por essa imposição do Estado enquanto protagonista dos processos de transformação social. Ao ocupar o lugar das classes sociais e assumir, no âmbito estatal, a função de direção, de exercício da hegemonia, operase um enfraquecimento da sociedade civil, diluem-se os limites entre interesse público e interesse privado e escancara-se o caráter de classe do Estado.

Além de subsidiar as análises acerca do processo de modernização capitalista no país, em termos históricos mais recentes, a noção de revolução passiva pode dar indicações analíticas para o processo de democratização, ao utilizá-la como critério de interpretação histórica (GRAMSCI, 2002). Em outras palavras, ao constituir-se num critério de interpretação para compreender episódios da história brasileira, o conceito de revolução passiva provê instrumentos analíticos indicativos dos traços decisivos da formação política e social do país.

Deste modo, neste estudo não se limita a utilização da noção gramsciana de revolução passiva ao período de consolidação do capitalismo, mas como instrumento de análise da democracia brasileira, do momento político de transição democrática efetuado no Brasil e os desdobramentos contemporâneos das relações sociopolíticas. Ter-se-ia uma revolução passiva no fato de que, mediante a intervenção legislativa do Estado foram introduzidas paulatinamente modificações na estrutura de organização política do país como resposta a um processo de esgotamento do regime político autoritário, acentuado pelo contexto de crise econômica, a crise do milagre econômico, a partir da década de 1970, e mobilização de segmentos organizados da sociedade civil. Para Gramsci (2002) o fato de o Estado, mesmo que limitado como potência, se coloque como dirigente em lugar do grupo social dominante é de máxima importância para o critério interpretativo de revolução passiva.

Além da conjuntura interna de correlações de forças, exercem determinação nesse processo também as influências externas, principalmente com relação aos interesses econômicos, pois não há como deslocar o país de sua inserção na ordem econômica internacional, tampouco desconsiderar determinações estruturais no âmbito superestrutural. A estratégia de crescimento econômico implementada no país foi baseada no endividamento externo contraído junto ao sistema financeiro privado internacional. Os anos de 1968-1973 foram marcados pelo milagre econômico brasileiro, estratégia sem sustentabilidade econômica em longo prazo, pois fundamentada na dependência do capital internacional. O desenvolvimento econômico-social adotado pelos governos militares reforçou a integração subordinada do Brasil à ordem capitalista internacional, por meio de um crescimento econômico dependente, conduzido segundo interesses imperialistas e balizado por ações sociopolíticas antidemocráticas. A conjuntura de crise econômica vivenciada no país a partir da segunda metade da década de 1970 é consequência do projeto desenvolvimentista colocado em curso pelo governo autoritário. Observa-se que, no processo histórico de modernização capitalista do país, o discurso ideológico adotado pelas classes dominantes é o de superação do subdesenvolvimento por meio do crescimento econômico, o qual dota de legitimidade política a mobilização de esforços e adoção de estratégias nacionais.

A crise do milagre econômico é expressão particular de um movimento mais geral de recessão do capital internacional. E a estratégia de enfrentamento adotada pelo regime militar foi aumentar o endividamento externo por meio de empréstimos com juros flutuantes, que variam conforme a alteração no mercado internacional. Negócio que, em 1979, em consequência de um excessivo aumento da taxa internacional de juros, criou os condicionantes econômicos que terminaram por fazer da próxima década uma década perdida. 
Para atender a necessidades geradas por um contexto de crise de relações econômicas internacionais, acrescido das consequências da política desenvolvimentista implantada pelo governo militar, impõe-se a necessidade de alteração das relações políticas. E é nesse contexto que o germe da sociedade civil brasileira encontra terreno fértil para se desenvolver de forma mais concreta na luta contra o regime político autoritário.

Apesar de reprimida por um regime político autoritário, a sociedade civil brasileira cresceu e se diversificou nesse período. A modernização da sociedade criou as forças, as bases necessárias para a luta contra o autoritarismo do Estado e pela democracia, "mais um caso do célebre feiticeiro que desencadeia forças que depois não é capaz de controlar" (COUTINHO, 1984, p. 88). Manifesta-se um duplo movimento que pode ser analisado como a coexistência de um projeto e um processo de democratização. Em meio a um contexto de crise orgânica, o governo autoritário põe em curso um projeto de abertura democrática, lento, gradual, arbitrário, sem grandes rupturas, conduzido pelo alto. No entanto, as pressões vindas de baixo, da crescente organização e mobilização da sociedade civil, fazem com que tome lugar na realidade social brasileira um processo que influencia a execução do projeto de abertura. Paradoxalmente, esse processo de acúmulo de forças da resistência democrática é viabilizado pela modernização capitalista do período ditatorial, a qual, por meio da transformação do Brasil num país urbano-industrial complexo e diferenciado, possibilitou a dinamização da organização de interesses (DURIGUETTO, 2007).

Se na transição política a concepção de democracia hegemônica foi a de uma transição democrática a ser construída pelo alto, concentrando nas mãos dos de cima o controle dos programas de abertura, a interpretação marxista, em particular a gramsciana, de sociedade civil e democracia é posicionada de forma antagônica a esta perspectiva. A democracia é pensada enquanto meio para construção de uma nova hegemonia, de um consenso majoritário construído a partir da pluralidade dos interesses e das organizações dos sujeitos populares, numa articulação entre sociedade civil, hegemonia e democracia. A construção e a consolidação de um regime de democracia política, nessa perspectiva, são vistas como possibilidade de superação das tendências elitistas, particularmente acentuadas no regime autoritário, e como pressuposto, que deve ser reposto e conservado e ao mesmo tempo aprofundado, para o avanço rumo a uma democracia de teor cada vez mais substantivo.

Uma noção de processualidade que se alinha ao conceito de guerra de posição desenvolvido por Gramsci, fundamenta o argumento de que se faz necessário consolidar e ampliar o processo de renovação democrática a partir das organizações populares. No sentido de uma "progressiva obtenção de posições no seio da sociedade civil como base para novos avanços, que gradativamente tornarão realista a questão da conquista democrática do poder de Estado pelas classes trabalhadoras" (DURIGUETTO, 2007, p. 156).

A partir da segunda metade da década de 1980 e adentrando aos anos 1990, diferentes concepções de sociedade civil e democracia revelam-se de forma mais acentuada e fundamentam o campo de disputas por determinações na realidade social, o que tornou o campo temático ainda mais complexo. O modo pelo qual o regime político autoritário reage às pressões "de baixo" é através de uma paulatina e controlada abertura democrática, por meio da qual o Estado, mais uma vez na história brasileira, desempenha a função de classe dirigente e conduz um longo processo de mudança do regime político, obtendo, dessa forma, o consenso à medida que assimila e responde a algumas das demandas dos grupos sociais não hegemônicos e mobilizados. $\mathrm{O}$ projeto de abertura democrática operou-se por meio de concessões capazes de permitir uma autorreforma que não alterasse a substância elitista do modo tradicional de fazer política no país. Esta característica levou à construção de superestruturas adequadas à dominação de uma restrita oligarquia sobre a maioria da população. E uma das consequências desse processo foi a geração de uma debilidade histórica da democracia no Brasil, o que coloca o desafio, ao conjunto das forças populares, de lutar para inverter essa tendência elitista da política brasileira e combater suas consequências nas várias esferas do ser social (COUTINHO, 1984).

Ao analisar a forma de transição do regime político autoritário para o democrático, nota-se que o Estado brasileiro desempenha o papel de "substituir as classes sociais em sua função de protagonista dos processos de transformação e o de assumir a tarefa de 'dirigir' politicamente as próprias classes economicamente dominantes" (COUTINHO, 2007, p. 204). Ou seja, no Brasil, as classes dominantes relegaram para o Estado a função de dominação política, processo ao qual Gramsci (2006) denomina de ditadura sem hegemonia, uma manifestação da revolução passiva em que o instrumento da transição pelo alto é o Estado e no qual há limitação da participação ativa das massas populares. O instrumento e o local da conciliação de classes no país é, historicamente, o Estado, em sentido restrito, do que se verifica o fortalecimento da sociedade política em detrimento da sociedade civil. No entanto, mesmo em processos de transição pelo alto faz-se necessário um mínimo de consenso, e o modo pelo qual se obtém esse mínimo consentimento é chamado de transformismo: "a assimilação pelo bloco no poder das frações rivais das próprias classes dominantes ou até mesmo de setores das classes subalternas", uma modalidade de desenvolvimento histórico que implica a exclusão das massas populares (COUTINHO, 2007, p. 205). Essa leitura possibilita considerar que, mesmo analisada enquanto um processo de revolução passiva, a institucionalização da democracia brasileira lança as sementes de novas 
rupturas, em um processo cumulativo e passível de novas sínteses. Trata-se de aplicar o conceito de revolução passiva enquanto critério interpretativo das "modificações moleculares, que, na realidade, modificam progressivamente a composição anterior das forças e, portanto, transforma-se em matriz de novas modificações" (GRAMSCI, 2002, p. 317).

O fim do longo período de transição democrática acontece como síntese de múltiplas determinações, intenso de contradições internas e influências externas. Mesmo conduzido pelo alto, como estratégia do Estado autoritário para controlar as mudanças políticas e sociais, a sociedade civil brasileira assume determinado grau de autonomia e mobilização na luta pela alteração do regime político ditatorial. Ao estender-se por mais de uma década, esse movimento operado pelo alto imprime características ao regime democrático síntese desse processo. Altera-se a institucionalidade política do país, culminando na nova Constituição Federal de 1988, mas, o que as análises dessas quase três décadas ininterruptas de regime democrático têm demonstrado é que a influência do processo histórico de relações estabelecidas entre Estado e sociedade civil exige mudanças ideológicas e culturais que se operam além da legalidade formalmente instituída.

É possível sintetizar que o que se operou a partir da transição democrática, no decorrer da década de 1990, foi um processo de consolidação de liberdades político-formais, de mudanças nas objetivações ou formas de relacionamento social que compõem o arcabouço institucional da democracia política. Configuração que se constitui em premissa fundamental para um processo de superação, de elaboração de novas sínteses, no sentido de aprofundamento da democracia. Existem implicações políticas desse processo de modernização conservadora e, de acordo com Simionatto (1998), essas contradições reaparecem sob nova roupagem a depender da conjuntura, na medida em que também se alteram as relações de forças postas na dinâmica da vida social.

Ao identificar o papel de centralidade assumido pelo

...no Brasil há um

fortalecimento do Estado em

detrimento da sociedade civil,

com ausência de uma iniciativa

popular unitária no

desenvolvimento da história.

Estado brasileiro no processo de formação da atual institucionalidade democrática é preciso levar em conta que este se localiza em um contexto particular de ampliação do Estado. O que impõe a necessidade de analisar o grau de "socialização da política" do contexto brasileiro, considerando as relações estabelecidas entre sociedade política e sociedade civil. Em outras palavras, o pensamento gramsciano pode subsidiar não apenas interpretações do passado, mediante os conceitos de revolução passiva e transformismo, mas também a análise do presente, pela noção de Estado ampliado a qual permite identificar algumas das características essenciais da formação social brasileira e fornece indicações para a elaboração de uma estratégia de luta democrática concebida como guerra de posição (COUTINHO, 2007).

Olhar para as relações sociopolíticas no que tange à democracia no Brasil, subsidiado pela teoria ampliada de Estado, permite interpretar que, consolidado legalmente o período de transição democrática e adentrando a década de 1990, a sociedade civil brasileira passa a contar com um amplo espectro de possibilidades institucionais de organização, complexificando o âmbito das análises das relações estabelecidas entre Estado e sociedade civil.

Como parte do processo de socialização da política na realidade brasileira está a multiplicação de organismos de democracia direta e o surgimento de sujeitos políticos coletivos de novo tipo (associações de moradores, comunidades religiosas de base, organizações não governamentais, fundações, fóruns, para citar alguns) os quais ganharam autonomia e representatividade. Esse fortalecimento da sociedade civil atribui legitimidade à luta pelo aprofundamento da democracia política, num movimento de diluição do poder político no âmbito da sociedade, por meio da participação democrática. A Constituição Federal de 1988 (CF/88) representa a normatização do pacto estabelecido entre sociedade civil e sociedade política e expressa, no que tange às relações políticas, a institucionalização de um regime democrático que alia mecanismos de democracia representativa e democracia direta. Variadas formas de participação política são previstas na CF/88, com naturezas diversas: Conselhos, Conferências, Orçamento Participativo, Plebiscito, Referendo, Consulta Pública, Audiência Pública, Projetos de Lei de Iniciativa Popular, Partidos Políticos, Sindicatos, Associações Civis, ONGs, Fóruns, Movimentos Sociais etc. Após a etapa de inscrever os direitos de participação da sociedade civil na CF/88, põe-se em curso o acirramento das contradições econômicas próprias da fase de crise estrutural do capital. E, em substituição ao ideário desenvolvimentista colocado em cheque entra em cena a hegemonia neoliberal.

O objetivo do programa neoliberal era o de retomar o crescimento econômico não apenas no Brasil, mas em todo o continente latino-americano, propondo solucionar a crise da dívida externa e a alta inflação por meio da liberalização econômica e de uma política de privatizações. Desse modo, a proposta desenvolvimentista de superação do subdesenvolvimento passa a ser negada e substituída pelo novo consen- 
so político neoliberal, liderado pela oligarquia financeira internacional e organizado em torno do Consenso de Washington (MARANHÃO, 2014).

A complexidade da conjuntura vivenciada no país a partir da redemocratização é evidenciada à medida que são considerados os fatores internos e externos que se fazem presentes. Como influência externa a globalização econômica se impõe limitando o poder dos Estados nacionais, redefinindo o padrão de regulação estatal da economia e promovendo reformas liberalizantes e, internamente, as pressões para a efetivação do status de cidadania pactuado na recém instituída legislação nacional geram um contexto de tensões e disputas. O programa de ajuste estrutural ao retrair a intervenção estatal na esfera social acarreta no aumento da pobreza e se coloca oposto às demandas emergentes pelo processo de abertura política, delineando a paradoxal configuração da década de 1990: instauração do regime político democrático, reconhecimento de direitos sociais, normatização de um sistema de proteção social, pactuados na $\mathrm{CF} / 88$, em contraponto à imposição da redução do gasto público e da adoção de medidas neoliberais. Para equacionar esta questão, o projeto neoliberal põe em curso uma apropriação ideológica da noção de sociedade civil, a qual passa a ser chamada para protagonizar processos de participação social instrumentalizada aos seus interesses. A sociedade civil brasileira passa a contar com múltiplas possibilidades de organização e institucionalização, mas, em um contexto sociopolítico de ajuste estrutural e formatação político-gerencial neoliberal, passa a ser ideologicamente valorizada em uma perspectiva muito diversa do que se processou na década anterior. Fundamentada em uma perspectiva de fragmentação, a totalidade do organismo social é segmentada em setores: um primeiro setor ocupado pelo Estado (âmbito da política), um segundo setor caracterizado pelo Mercado (âmbito da economia), e, a sociedade civil transformada em terceiro setor (des-politizada e des-economizada), constituída em espaço de integração cidadã, caracterizada pela promoção de interesses coletivos, mas diferenciada do Estado e do Mercado. Para Montaño (2014, p. 42), trata-se de um termo ideológico que esconde um projeto político (neoliberal) e esta ideologia materializa-se nos projetos do terceiro setor. Uma noção ideológica de sociedade civil enquanto lugar das subjetividades, de parcerias, "da liberdade e democracia formais (do liberalismo), onde os sujeitos poderiam desenvolver a experiência participacionista, ampliando suas potencialidades pessoais para resolver seus problemas, [de forma] individual".

Nesse ponto a interpretação de sociedade civil fundamentada na perspectiva gramsciana de luta pela hegemonia possibilita uma outra compreensão, que não separa sociedade civil de sociedade política, como se fosse possível que uma se desenvolvesse sem íntima conexão com a outra. Mas no entendimento de que a construção de uma nova hegemonia implica sua construção tanto na sociedade civil quanto no Estado. Além disso, ao reconhecer a sociedade civil como campo de luta política pela hegemonia, desmistifica-se uma percepção virtuosa desta em oposição ao Estado e é possível reconhecer que sua natureza é, também, classista e contraditória. A concepção gramsciana do termo identifica a sociedade civil como uma esfera pública política, a qual juntamente com a sociedade política, em sentido estrito, constitui o Estado, em contraposição ao entendimento neoliberal de sociedade civil como sinônimo de terceiro setor, como uma esfera pública acrítica, apolítica e aclassista.

Retomando o contexto brasileiro e adentrando aos anos 2000, apesar da vitória eleitoral presidencial do Partido dos Trabalhadores (PT), em 2002, o que se processou no país foi a continuidade e mesmo o aprofundamento da política econômica neoliberal. É preciso pontuar que o PT representava à época um partido político engajado com as lutas progressistas e propunha um projeto político nacional de enfrentamento à desigualdade social e superação da histórica heteronomia econômica do país. O partido liderou a oposição parlamentar durante os dois mandatos de Fernando Henrique Cardoso, constituindo-se na resistência política ao curso neoliberal de ajustes estruturais da economia, privatizações e reforma do Estado (MARANHÃO, 2014). A vitória nas eleições presidenciais da coalizão liderada pelo Partido dos Trabalhadores gerou grandes expectativas de mudanças políticas e sociais, principalmente na condução macroeconômica neoliberal do país. No entanto, o que se observou durante os dois mandatos do presidente Lula (2003-2010), sucedido pelo governo Dilma Rousseff (2011 - 2016), foi uma condução da política econômica de cunho conservador, voltada para o ajuste fiscal para a geração de superávit primário, canalizado para pagar a dívida externa. Ao reafirmar a política econômica herdada do governo FHC, o governo encabeçado pelo Partido dos Trabalhadores não reverteu, antes aprofundou, a orientação macroeconômica implementada durante os dois mandatos de Fernando Henrique Cardoso.

É preciso pontuar que, se a condução da política econômica se manteve sem rupturas com o período anterior, a condução da política social experimentou significativas alterações, o que possibilitou ao PT angariar legitimidade na continuidade do governo, que traz à tona a impossibilidade de tratar a economia separada da política, e que a necessidade de elaboração de consensos se impõe aos que ocupam o aparelho estatal. Para Nogueira (2013), a estratégia de desenvolvimento empreendida teve como eixo central o social, em que a expansão das forças produtivas deixa de ser o principal objetivo a alcançar, embora ainda relevante, mas 
subordinada ao desenvolvimento social. Os fatores que impulsionam o crescimento nesse modelo de desenvolvimento encontram-se na ampliação do consumo de massas fundada na redistribuição da renda, um movimento de maior legitimidade política e maior prioridade macroeconômica pela área social.

A questão da legitimidade democrática em um contexto de grande desigualdade social impõe a necessidade de discutir padrões éticos e aceitáveis para a sociabilidade humana, pois nem tudo pode ser bem de mercado numa sociedade que se afirma democrática (COSTA, 2006), diante do que o capital necessita criar mecanismos que gerem crescimento econômico e amenizem as expressões da questão social. O que ocorre no Brasil por meio da readequação de propostas de crescimento econômico e social, de um novo pacto para o desenvolvimento o qual resgata o potencial mitificador da ideologia desenvolvimentista para ocultar conflitos de classe e construir consensos políticos na condução da modernização capitalista do país (MARANHÃO, 2014).

A reatualização do discurso desenvolvimentista no Brasil cumpre a função de elaborar consensos para a continuidade do projeto político de modernização capitalista em um país subdesenvolvido que experimentou a falência da promessa neoliberal. Trata-se de um discurso travestido de intenções progressistas que concilia desenvolvimento econômico e social, sem significar um rompimento com o núcleo central das políticas neoliberais, mas oferecendo uma "união sincrética entre políticas econômicas incentivadoras dos mecanismos de liberalização do mercado e políticas de proteção social compensatórias e de alívio da condição de miséria" (MARANHÃO, 2014, p. 328).

Nesse contexto, o papel desempenhado pela sociedade civil coloca-se como fundamental, pois é no palco da sociedade civil que são travados os embates das correlações de forças estabelecidas em cada conjuntura, as disputas por projetos societários, as resistências diante das reformas do Estado, a elaboração de consensos. O Estado, na perspectiva gramsciana, é um espaço a ser apropriado pelo movimento transformador, sob a perspectiva de uma nova hegemonia. Em se tratando do contexto sociopolítico da última década, é preciso lançar o foco da análise sobre as grandes mobilizações desencadeadas a partir das Jornadas de Junho/2013 no Brasil, as quais, em uma sociedade globalizada e conectada em rede, relacionam-se a diversas outras expressões mundo a fora: A Primavera Árabe, os Indignados na Espanha, Occupy Wall Street nos Estados Unidos etc. ${ }^{1}$ Nestes diversos países, assim como nas cidades brasileiras, foram postos em questão os modelos de desenvolvimento e as formas de fazer política. Para Castells (2013), o tradicional modelo de democracia representativa, baseado em estruturas verticais e centralizadas, dá sinais de esgotamento, ao que as mobilizações em massa têm reagido com propostas de organizações horizontais, sem personificação de lideranças nem comando de partidos ou comitês centrais. São movimentos que evidenciam um contexto de crise das tradicionais estruturas de representação coletiva de interesses populares, contexto em que a democracia é limitada pelos verdadeiros poderes que agem apesar dela e anulam a soberania popular. É a denominada crise de representatividade das instituições políticas, esvaziadas de seu potencial democratizador e colonizadas pelo poder econômico.

No Brasil, as Jornadas de Junho, onda de protestos que tomou o país em 2013, levou às ruas milhões de brasileiros, jovens em sua maioria, em um protesto maciço contra as deficiências do sistema de prestação de serviços públicos. Houve registros de manifestações em mais de cem cidades brasileiras, as quais tiveram como foco espontâneo a luta pela melhoria da qualidade dos serviços públicos como transporte, educação, saúde e segurança. Os protestos contra a precariedade do sistema de prestação de serviços públicos ignoraram parlamentares, sindicatos e partidos políticos. Ainda que de modo espontâneo e improvisado, deixou evidente que se dirigia contra a forma de estruturação do governo representativo no país. O descontentamento não canalizado pela representação política por parte daqueles que são "alijados do poder de decisão sobre seu destino" gerou um movimento de tomada deste destino com seu próprio corpo, por meio da ação direta, da ocupação do espaço público urbano e, por meio desta, da forçada ação política (HARVEY, 2013, p. 10).

Se o espaço público institucional, o espaço constitucionalmente designado para a deliberação, é ocupado pelos interesses de uma elite dominante em processo de perda de hegemonia, os movimentos contra-hegemônicos, ainda que não formem uma massa coesa, ocupam o espaço urbano e os prédios simbólicos com vistas a forçar a abertura de um novo espaço público não limitado à internet. Castells $(2013$, p. 11) parte do pressuposto de que, se as relações de poder são constitutivas da sociedade, aqueles que detém o poder constroem as instituições segundo seus valores e interesses, de modo que o poder é exercido pela coerção e também pela construção de significados na mente das pessoas, por meio de mecanismos de manipulação simbólica, os quais constituem-se em uma fonte de poder mais decisiva e estável: "Poucos sistemas institucionais podem perdurar baseados unicamente na coerção. Torturar corpos é menos eficaz que moldar mentalidades. [...] É por isso que a luta fundamental pelo poder é a batalha pela construção de significado na mente das pessoas" (CASTELLS, 2013,). Em uma perspectiva gramsciana, dizer que as relações de poder são constitutivas das instituições da sociedade significa dizer que os aparelhos privados de hegemonia elaboram consensos necessários para a condução do bloco histórico e que, uma vez que as sociedades são conflitivas e contraditórias, onde há poder há 
também a possibilidade de enfrentamento, da correlação de forças e de elaboração de novas hegemonias. É necessário pontuar que, se em 2013 as multidões foram às ruas numa perspectiva coletiva e apartidária, agudizada pela demanda por oferta de serviços e colocando em questão a legitimidade das instituições democráticas, essa caracterização não pode ser transposta para as manifestações que se seguiram nos anos posteriores. Nos limites desse trabalho, o que importa considerar é a retomada do protesto de rua como instrumento de pressão política, sendo incorporado ao repertório de ação da sociedade civil, assimilado ideologicamente tanto à direita, quanto à esquerda.

\section{Conclusão}

O resultado da redemocratização do país na década de 1980, ainda que tenha instituído uma forma democrática de organização societária, é limitado em seu conteúdo político, consequência do processo de correlações de forças estabelecido ao longo da década de 1990, período em que a sociedade civil brasileira fragmenta-se e é fragilizada em um contexto de hegemonia neoliberal. De 1990 a 2010 vivencia-se um ciclo de vinte anos de expectativa da proposta de democracia pactuada na Constituição Federal de 1988, que tem sua efetividade impedida pelo projeto neoliberal. A retração do Estado e o não cumprimento do projeto democrático constitucional colocam-se como base para a instalação de um cenário de crise e de volta das manifestações das multidões nas ruas como forma de expressão política da sociedade civil.

Passadas três décadas, a sociedade civil brasileira se debate entre diferentes formas e conteúdos: as resistências populares em defesa de uma democracia de significado substantivo; e a sociedade civil que assume a função designada pela direção do projeto político hegemônico neoliberal, desempenhando papel fundamental para sua manutenção.

O argumento de Luiz (2010, p. 82) é o de que "é necessário criar uma nova cultura sobre o entendimento de sociedade civil, a qual represente maiores possibilidades de consolidação do processo democrático a partir de suas potencialidades", diante do qual se evidencia ainda um longo caminho a percorrer na luta pela ampliação da socialização da política no Brasil e pela consolidação de uma sociedade civil protagonista desse processo, e o destino deste depende dos desdobramentos dessa luta. Para tanto, neste estudo, por exemplo, as categorias revolução passiva, transição pelo alto, ditadura sem hegemonia, modernização conservadora se mostraram atuais para entender alguns elementos dos processos sociopolíticos brasileiros contemporâneos. O desafio assumido neste trabalho, conforme ensina Coutinho (2007), é o de pensar os problemas contemporâneos da vida social e política de um contexto local a partir do legado de Gramsci, tomando-o como subsídio para interpretar as questões postas pela ordem presente.

\section{Referências}

AGGIO, A. (Org.). Gramsci: a vitalidade de um pensamento. São Paulo: Editora UNESP, 1998.

BIANCHI, A. Revolução passiva: o pretérito do futuro. In: Crítica Marxista, São Paulo. Revan, v.1, n.23, 2006.

CASTELLS, M. Redes de indignação e esperança: movimentos sociais na era da internet. Tradução Carlos Alberto Medeiros. Rio de Janeiro: Zahar, 2013.

COUTINHO, C. N. A democracia como valor universal e outros ensaios. Rio de Janeiro: Salamandra, 1984.

COUTINHO, C. N. Socialismo e Democracia: a atualidade de Gramsci. In: AGGIO, A. (Org.). Gramsci: a vitalidade de um pensamento. São Paulo: Editora UNESP, 1998.

COUTINHO, C. N. Gramsci: um estudo sobre seu pensamento político. Rio de Janeiro: Civilização Brasileira, 2007.

COSTA, L. C. Os impasses do Estado Capitalista. Uma análise sobre a reforma do Estado no Brasil. Ponta Grossa: UEPG e Cortez, 2006.

FAORO, R. Os Donos do Poder. São Paulo: Globo; Publifolha, 2000.

DURIGUETTO, M. L. Sociedade civil e democracia: um debate necessário. São Paulo: Cortez, 2007.

FERNANDES, F. A revolução burguesa no Brasil: ensaio de interpretação sociológica. Rio de Janeiro: Zahar Editores, 1987.

GRAMSCI, A. Cadernos do Cárcere. Tradução de Carlos Nelson Coutinho e Luiz Sérgio Henriques. v. 5. Rio de Janeiro: Civilização Brasileira, 2002.

GRAMSCI, A. Cadernos do Cárcere. Tradução de Carlos Nelson Coutinho e Luiz Sérgio Henriques v. 1. Rio de Janeiro: Civilização Brasileira, 2006.

HARVEY, D. A liberdade da cidade. In: MARICATO, E. [et. al.]. Cidades rebeldes: Passe Livre e as manifestações que tomaram as ruas do Brasil. São Paulo: Boitempo: Carta Maior, 2013.

LUIZ, D. E. C. (Org.). Sociedade Civil e Democracia: expressões contemporâneas. São Paulo: Veras, 2010. 
MARANHÃO, C. A ideologia neodesenvolvimentista: crise do capital, novas estratégias e velhas promessas da classe dominante brasileira. In: MONTAÑO, C. O canto da sereia: crítica à ideologia e aos projetos do "terceiro setor". São Paulo: Cortez, 2014. MONTAÑO, C. O canto da sereia: crítica à ideologia e aos projetos do "terceiro setor". São Paulo: Cortez, 2014.

NOGUEIRA, M. A. As ruas e a democracia. Brasília: Fundação Astrogildo Pereira (FAP); Rio de Janeiro: Contraponto, 2013. ROLNIK, R. As vozes das ruas: as revoltas de junho e suas interpretações. In: MARICATO, E. [et. al.]. Cidades rebeldes: Passe Livre e as manifestações que tomaram as ruas do Brasil. São Paulo: Boitempo: Carta Maior, 2013.

SIMIONATTO, I. Estado e Democracia. In: COSTA, L. C. Estado e democracia: pluralidade de questões. Ponta Grossa: Editora UEPG, 2008.

SIMIONATTO, I. O social e o político no pensamento de Gramsci. In: AGGIO, A. (Org.). Gramsci: a vitalidade de um pensamento. São Paulo: Edit.

\section{Nota}

1 A conexão entre o movimento no Brasil e outros tantos espalhados pelo planeta está na transformação de espaços públicos urbanos em palcos de protestos majoritariamente formados por jovens, mobilizados por meio de redes sociais, sem a presença de partidos, sindicatos ou organizações de massa tradicionais (ROLNIK, 2013).

\section{Emilie Faedo Della Giustina}

emiliefaedo@hotmail.com

Doutoranda em Ciências Sociais Aplicadas na Universidade Estadual de Ponta Grossa, Paraná (UEPG)

\section{Danuta Estrufika Cantóia Luiz}

danutaluiz88@gmail.com

Professora do Curso de Serviço Social e do Programa de Pós Graduação em Ciências Sociais Aplicadas da Universidade Estadual de Ponta Grossa, Paraná (UEPG)

\section{UEPG}

Campus Central - Praça Santos Andrade n. 1

Ponta Grossa - Paraná - Brasil

CEP: 84.010-919 